\title{
Hospital admission for diabetic ketoacidosis or severe hypoglycemia in 31330 young patients with type 1 diabetes
}

\author{
Beate Karges ${ }^{1,2,3}$, Joachim Rosenbauer ${ }^{4}$, Paul-Martin Holterhus ${ }^{5}$, Peter Beyer ${ }^{6}$, \\ Horst Seithe ${ }^{7}$, Christian Vogel ${ }^{8}$, Andreas Böckmann ${ }^{9}$, Dirk Peters ${ }^{10}$, Silvia Müther ${ }^{11}$, \\ Andreas Neu ${ }^{12}$ and Reinhard W Holl ${ }^{13}$ on behalf of the DPV Initiative ${ }^{+}$ \\ ${ }^{1}$ Division of Endocrinology and Diabetes and ${ }^{2}$ Department of Gynecological Endocrinology and Reproductive \\ Medicine, Medical Faculty, RWTH Aachen University, German Center for Diabetes Research (DZD), Pauwelsstraße 30, \\ D 52074 Aachen, Germany, ${ }^{3}$ Department of Pediatrics, Bethlehem Krankenhaus, Stolberg, Germany, \\ ${ }^{4}$ Institute for Biometrics and Epidemiology, German Diabetes Center, Leibniz Center at University of Düsseldorf, \\ Düsseldorf, Germany, German Center for Diabetes Research (DZD), ${ }^{5}$ Division of Pediatric Endocrinology and \\ Diabetes, Department of Pediatrics, University Hospital Schleswig-Holstein, Christian-Albrechts University Kiel, Kiel, \\ Germany, ${ }^{6}$ Department of Pediatrics, Evangelisches Krankenhaus Oberhausen, Oberhausen, Germany, \\ ${ }^{7}$ Department of Pediatrics, Klinikum Nürnberg Süd, Nürnberg, Germany, ${ }^{8}$ Department of Pediatrics, Klinikum \\ Chemnitz, Chemnitz, Germany, ${ }^{9}$ Department of Pediatrics, Klinikum Konstanz, Konstanz, Germany, \\ ${ }^{10}$ Department of Pediatrics, Asklepios Klinik St. Augustin, St. Augustin, Germany, ${ }^{11}$ Diabetes Center for Children \\ and Adolescents, DRK Kliniken Berlin Westend, Berlin, Germany, ${ }^{12}$ Department of Pediatrics, University of \\ Tübingen, Tübingen, Germany and ${ }^{13}$ Institute of Epidemiology and Medical Biometry, ZIMBT, \\ German Center for Diabetes Research (DZD), University of Ulm, Ulm, Germany \\ ${ }^{\dagger}$ (Members of the DPV Initiative are presented in the Acknowledgements section)
}

Correspondence
should be addressed
to B Karges
Email
bkarges@ukaachen.de

\begin{abstract}
Objective: To investigate rates and risk factors of hospital admission for diabetic ketoacidosis (DKA) or severe hypoglycemia in young patients with established type 1 diabetes.

Design: In total, 31330 patients with type 1 diabetes (median age 12.7 years) from the Diabetes Patienten Verlaufsdokumentation (DPV) Prospective Diabetes Registry treated between 2011 and 2013 in Germany were included. Methods: Admission rates for DKA ( $\mathrm{pH}<7.3$ or bicarbonate $<15 \mathrm{mmol} / \mathrm{l}$ ) and severe hypoglycemia (requiring assistance from another person) were calculated by negative binomial regression analysis. Associations of DKA or hypoglycemia with patient and treatment characteristics were assessed by multivariable regression analysis.

Results: The mean admission rate for DKA was $4.81 / 100$ patient-years $(95 \% \mathrm{Cl}, 4.51-5.14)$. The highest DKA rates were observed in patients with $\mathrm{HbA} 1 \mathrm{c} \geq 9.0 \%$ (15.83 (14.44-17.36)), age 15-20 years (6.21 (5.61-6.88)) and diabetes duration of $2-4.9$ years (5.60 (5.00-6.27)). DKA rate was higher in girls than in boys (5.35 (4.88-5.86) vs $4.34(3.95-4.77), P=0.002)$, and more frequent in migrants than in non-migrants $(5.65$ (4.92-6.49) vs 4.57 (4.23-4.93), $P=0.008)$. The mean admission rate for severe hypoglycemia was $1.45 / 100$ patient-years (1.30-1.61). Rates were higher in migrants compared to non-migrants (2.13 (1.72-2.65) vs $1.28(1.12-1.47), P<0.001)$, and highest in individuals with severe hypoglycemia within the preceding year (17.69 (15.63-20.03) vs patients without preceding hypoglycemia $0.42(0.35-0.52), P<0.001)$. Differences remained significant after multivariable adjustment.

Conclusions: The identification of at-risk individuals for DKA (patients with high HbA1c, longer diabetes duration, adolescents, girls) and for severe hypoglycemia (patients with preceding severe hypoglycemia, migrants) may facilitate
\end{abstract} targeted diabetes counselling in order to prevent these complications. 


\section{Introduction}

Ketoacidosis and severe hypoglycemia are common and potentially life-threatening complications in patients with type 1 diabetes receiving insulin treatment (1). Diabetic ketoacidosis (DKA) accounts for 13\% $(2,3)$ to $19 \%(4)$ of disease-related mortality and occurs at a rate of $1-10 / 100$ patient-years in children and adolescents with established diabetes remaining largely constant within the last decade $(1,5,6,7)$. In contrast, the incidence of severe hypoglycemia has decreased during the past decade and recent reports refer to rates of 16-20/100 patient-years for severe hypoglycemia (defined as requiring assistance from another person) and 2-8/100 patient-years for hypoglycemic coma (loss of consciousness or seizures) $(1,7,8$, $9,10,11)$, accounting for $4-10 \%(2,3,4,12)$ of diseaserelated mortality.

Hospital admission for DKA and severe hypoglycemia may be influenced by a wide spectrum of risk determinants. Previous studies identified patient characteristics including sex, age, diabetes duration and ethnic origin as risk factors of hospitalization for DKA and of severe hypoglycemia (defined as loss of consciousness or seizure or hospital visit) $(6,7)$. In addition, treatmentrelated variables such as $\operatorname{HbA1c}(6,7)$ and insulin treatment regimen (use of insulin pump or multiple daily insulin injections) $(7,10,13,14)$ have been shown to affect the risk of DKA and severe hypoglycemia. These studies were mainly center-based and performed in small cohorts of children and adolescents with type 1 diabetes $(6,7,10,13,14)$.

Identification of valid predictors for DKA and severe hypoglycemia may offer the opportunity to prevent both acute complications of type 1 diabetes in high-risk individuals. We conducted a population-based study in a large cohort of more than 30000 young patients with established type 1 diabetes to analyze the rates and potential risk markers of hospitalization for DKA and severe hypoglycemia.

\section{Subjects and methods}

The Diabetes Patienten Verlaufsdokumentation (DPV) Prospective Documentation Initiative of diabetes care in Germany has prospectively followed patients with diabetes mellitus since $1995(1,8)$. Analysis of anonymized data was approved by the Ethics Committee of Ulm University, Ulm, Germany. For this study, inclusion criteria were the clinical diagnosis of type 1 diabetes mellitus; age at onset of diabetes $>6$ months; age $0.5-20$ years; diabetes duration more than 2 weeks and treatment in any period between 1st January 2011 and 31st December 2013 in Germany. For each patient, data of the first calendar year of follow-up within this period were analyzed. Applying these criteria, data of 31330 patients from 302 centers were available for cross-sectional analysis.

Hospital admissions for DKA or severe hypoglycemia were investigated in these patients with established type 1 diabetes. Ketoacidosis was defined as $\mathrm{pH}<7.3$ or bicarbonate $<15 \mathrm{mmol} / \mathrm{l}$. DKA at onset of type 1 diabetes was excluded. Severe hypoglycemia was defined as requiring assistance from another person to actively administer carbohydrates, glucagon or i.v. glucose (11). HbA1c values were mathematically standardized to the DCCT reference range $4.05-6.05 \%$ using the multipleof-the-mean transformation method (8). For each patient, $\mathrm{HbA1c}$ values were averaged per year of follow-up.

In separate analyses, rates of ketoacidosis and severe hypoglycemia were estimated stratified by sex, age groups, diabetes duration, migration background defined as place of birth of one or both parents outside of Germany, treatment regimen, HbA1c groups and history of one or more events of severe hypoglycemia within the preceding year was included in the analysis.

For descriptive analysis median with quartiles were calculated for continuous variables and percentages for categorical variables. Rates of DKA and severe hypoglycemia were expressed per 100 patient years with 95\% CI assuming negative binomial distribution of events. Associations of ketoacidosis and severe hypoglycemia with age, sex, diabetes duration and migration background were assessed by multivariable negative binomial regression analysis (model 1). Further regression analyses additionally included treatment regimens (model 2) and HbA1c category (model 3). Two-factor interactions of independent variables were also explored in the regression models. In addition, the association between hospital admission for severe hypoglycemia and one or more event of severe hypoglycemia within the preceding year was assessed. Results of regression analyses were presented as adjusted rates (estimated for each variable using observed marginal distribution in the study population for all other variables in the model) or relative risks (RRs) including Wald $95 \%$ CI. $P$ values of two-tailed tests $<0.05$ were considered statistically significant. All analyses were performed with SAS for Windows Version 9.4 (SAS Institute, Cary, NC, USA). 
Table 1 Characteristics of type 1 diabetes patients treated between 2011 and 2013.

\begin{tabular}{|c|c|}
\hline Characteristics & Results \\
\hline Number of patients & 31330 \\
\hline Sex (male) $(\%)$ & 52.8 \\
\hline Age (years); median (quartiles) & $12.7(9.2 ; 15.6)$ \\
\hline $\begin{array}{l}\text { Diabetes duration (years); } \\
\text { median (quartiles) }\end{array}$ & $3.2(0.8 ; 6.7)$ \\
\hline Migration background (\%) & 20.1 \\
\hline \multicolumn{2}{|l|}{ Insulin treatment regimen $(\%)$} \\
\hline $1-3$ insulin injection time points per day & 6.5 \\
\hline$\geq 4$ insulin injection time points per day & 57.5 \\
\hline Insulin pump therapy & 36.0 \\
\hline $\begin{array}{l}\mathrm{HbA} 1 \mathrm{c}(\%)^{\mathrm{a}} ; \text { median (quartiles), } n=30814 \\
\quad(\mathrm{mmol} / \mathrm{mol})\end{array}$ & $\begin{array}{l}7.8(7.0 ; 8.8) \\
(62(53 ; 73))\end{array}$ \\
\hline In girls, $n=14537$ & $7.8(7.0 ; 8.9)$ \\
\hline In boys, $n=16277$ & $7.7(7.0 ; 8.8)$ \\
\hline $\begin{array}{l}\text { In patients with migration background, } \\
n=6190\end{array}$ & $7.9(7.1 ; 9.0)$ \\
\hline In non-migrants, $n=24624$ & $7.7(7.0 ; 8.8)$ \\
\hline In patients using insulin pumps, $n=11077$ & $7.7(7.0 ; 8.5)$ \\
\hline $\begin{array}{l}\text { In patients with insulin injections, } \\
n=19737\end{array}$ & $7.8(7.0 ; 9.0)$ \\
\hline
\end{tabular}

${ }^{a}$ DCCT reference range $4.05-6.05 \%$. Conversion for $\mathrm{HbA} 1 \mathrm{c}(\mathrm{mmol} / \mathrm{mol})=$ $(\operatorname{HbA1c}(\%)-2.15) \times 10.929$.

\section{Results}

\section{Study population}

In total, 31330 patients (median 12.7 years and range 0.6-20 years) were included in the study. Clinical characteristics of the study population are shown in Table 1. A total of 30814 patients had available HbA1c measurements with a median of $4(2 ; 5)$ HbA1c measurements per calendar year. During a mean observation period of 0.77 years, 1159 events of acute hospitalization for DKA and 345 events for severe hypoglycemia were documented in children and adolescents with established type 1 diabetes mellitus. The mean crude rate of hospital admission for DKA in these patients was 4.81 (95\% CI, 4.51-5.14)/100 patient-years. Mean crude rate of admission because of severe hypoglycemia was 1.45 (95\% CI, 1.30-1.61)/100 patient-years. To investigate the admission rates for DKA and severe hypoglycemia in specific patient groups, the study population was stratified according to variables in Table 2 .

\section{Patient-related predictors of ketoacidosis}

Girls had higher unadjusted admission rates for DKA compared to boys (Fig. 1A), which remained significant after multivariable adjustment for demographic variables in model $1(P=0.001)$, additional adjustments for treatment regimens in model $2(P=0.002)$ and for HbA1c in model $3(P=0.02)$ (Table 3$)$. Boys had a $14-20 \%$ lower risk of admission for DKA compared to girls depending on the regression model used (Table 3). Unadjusted hospitalization rates for ketoacidosis increased with age from age group 5-9.9 to 10-14.9 years and to 15-20 years (Fig. 1B). After multivariable adjustment, DKA rates remained higher in patients aged 10-14.9 years compared to individuals aged 5-9.9 years in model $1(P<0.001)$, model $2(P<0.001)$ and model $3(P=0.02)$ (Table 3$)$.

Admission rates for DKA increased in patients with diabetes duration $>1$ year and was highest in individuals with diabetes duration of 2-4.9 years (Fig. 1C). DKA rate remained high after diabetes duration of $\geq 5$ years (5.47/100 patient years). After multivariable adjustment, differences for ketoacidosis admission rates remained significant if diabetes duration of $<1$ year was compared to a duration of 1-1.9 years in regression model 1 $(P=0.004)$, model $2(P=0.004)$ and model $3(P<0.001)$ (Table 3). Individuals with migration background had higher unadjusted hospitalization rates for DKA compared

Table 2 Patient groups for stratified analyses.

\begin{tabular}{|c|c|}
\hline Patient group & $\boldsymbol{n}(\%)$ \\
\hline Girls & $14786(47.2)$ \\
\hline Boys & $16544(52.8)$ \\
\hline \multicolumn{2}{|l|}{ Age (years) } \\
\hline $0.5-4.9$ & $2221(7.1)$ \\
\hline $5-9.9$ & 7097 (22.7) \\
\hline $10-14.9$ & 12445 (39.7) \\
\hline $15-20$ & $9567(30.5)$ \\
\hline \multicolumn{2}{|c|}{ Diabetes duration (years) } \\
\hline$<1$ & $9251(29.5)$ \\
\hline $1-1.9$ & $3083(9.8)$ \\
\hline $2-4.9$ & $7742(24.7)$ \\
\hline$\geq 5$ & $11254(35.9)$ \\
\hline \multicolumn{2}{|c|}{ Migration background } \\
\hline Yes & $6298(20.1)$ \\
\hline No & $25032(79.9)$ \\
\hline \multicolumn{2}{|c|}{ Insulin treatment regimen } \\
\hline Insulin pump & $11281(36.0)$ \\
\hline Insulin injections & $20049(64.0)$ \\
\hline \multicolumn{2}{|c|}{$\mathrm{HbA} 1 \mathrm{c}^{\mathrm{a}}(\%)$ (mmol/mol) } \\
\hline$<6.0(<42)$ & $1361(4.4)$ \\
\hline $6.0-6.9(42-52)$ & $6392(20.7)$ \\
\hline $7.0-7.9(53-63)$ & $9670(31.4)$ \\
\hline $8.0-8.9(64-74)$ & $6549(21.3)$ \\
\hline$\geq 9(\geq 75)$ & $6842(22.2)$ \\
\hline \multicolumn{2}{|c|}{ History of severe hypoglycemia } \\
\hline Yes & $1470(4.7)$ \\
\hline No & $29860(95.3)$ \\
\hline
\end{tabular}

${ }^{\text {a }}$ Missing values in $n=516$ patients. 

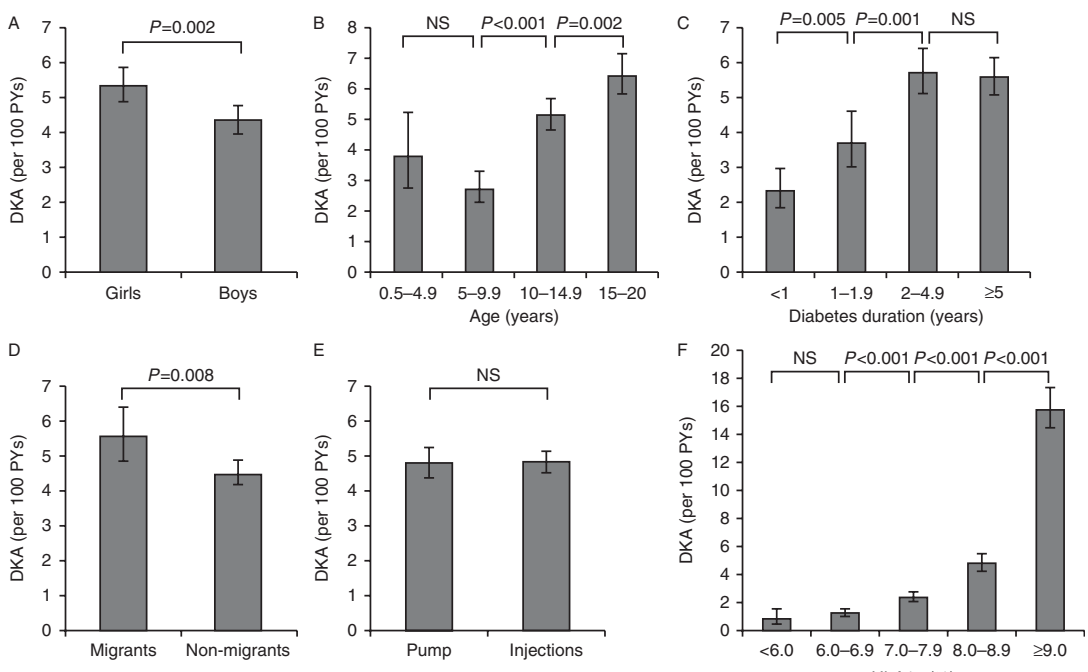

$\mathrm{HbA1c}(\%)$

\section{Figure 1}

Unadjusted rates of hospital admission for diabetic ketoacidosis (DKA). Rates per 100 patient-years (PYs) with $95 \% \mathrm{Cl}$ were stratified for: (A) sex, (B) age, (C) diabetes duration,

to patients without migration background (Fig. 1D). These differences remained significant in regression model 1 $(P=0.004)$ and model $2(P=0.005)$ but not after adjustment for HbA1c in model $3(P=0.17)$ (Table 3). Taken together, these results identify girls, adolescents, patients after the remission phase and migrants as individuals at risk of hospital admission for DKA.

\section{Treatment-related risk of ketoacidosis}

There were no differences between patients using insulin pumps and individuals using insulin injections for unadjusted ketoacidosis admission rates $(P=0.86$; Fig. 1E), and after multivariable adjustment in regression model $2(P=0.97$; Table 3$)$. However, regression analysis including HbA1c (model 3) revealed moderately higher ketoacidosis admission rates in individuals with insulin pumps (3.23/100 patient-years) compared to patients with insulin injections $(2.77 / 100$ patient-years, $P=0.03)$.

Individuals with $\mathrm{HbA} 1 \mathrm{c}$ values $\geq 9.0 \%$ had highest unadjusted ketoacidosis admission rates when compared to patients with lower HbA1c groups (Fig. 1F). Strikingly, ketoacidosis rates nearly exponentially rose with increasing HbA1c. Patients with HbA1c $\geq 9.0 \%$ had more than 20 -fold higher rates than individuals with $\mathrm{HbA1c}<6.0 \%$. These results were confirmed after multivariable adjustment in
(D) migration background, $(E)$ insulin treatment regimen and (F) $\mathrm{HbA} 1 \mathrm{c}$. Conversion for $\mathrm{HbA} 1 \mathrm{c}(\mathrm{mmol} / \mathrm{mol})=$ $($ HbA1c $(\%)-2.15) \times 10.929$. NS, not significant.

regression model 3 (Table 3), identifying high HbA1c as strongest predictor of hospital admission for DKA.

\section{Patient-related predictors of admission for severe hypoglycemia}

There were no differences between girls and boys for unadjusted hypoglycemia admission rates (Fig. 2A) and adjusted admission rates in model $1(P=0.54)$, model 2 $(P=0.59)$ and model $3(P=0.60)$ (Table 4$)$. Unadjusted hospitalization rates for severe hypoglycemia increased with age (Fig. 2B) but these differences did not reach significance. After multivariable adjustment, rates for severe hypoglycemia were higher in adolescents aged 15-20 years compared to patients aged $0.5-4.9$ years in regression model $1(P=0.02)$, model $2(P=0.046)$ and model $3(P=0.04)$, while comparison to other age groups revealed no differences in model $1(P \geq 0.07)$, model 2 $(P \geq 0.11)$ and model $3(P \geq 0.09)$ (Table 4$)$.

There were no differences in unadjusted hospital admission rates for severe hypoglycemia for patient groups with different diabetes duration (Fig. 2C), while regression analyses revealed higher hospitalization rates for patients with a diabetes duration of 2-4.9 years compared to a duration of $>5$ years in model $1(P=0.02)$, in model 2 $(P=0.03)$ and in model $3(P=0.04)$ (Table 4$)$. Taken together, 
Table 3 Adjusted rates and relative risks (RRs) of hospital admission for diabetic ketoacidosis. Results from $n=30814$ individuals with $\mathrm{HbA} 1 \mathrm{c}$ measurements.

\begin{tabular}{|c|c|c|c|c|c|c|}
\hline \multirow[b]{2}{*}{ Patient group } & \multicolumn{2}{|c|}{ Model $1^{a}$} & \multicolumn{2}{|c|}{ Model $2^{b}$} & \multicolumn{2}{|c|}{ Model $3^{c}$} \\
\hline & $\begin{array}{c}\text { Rate per } 100 \text { patient- } \\
\text { years }(95 \% \mathrm{Cl})\end{array}$ & $\mathrm{RR}(95 \% \mathrm{Cl})$ & $\begin{array}{c}\text { Rate per } 100 \text { patient- } \\
\text { years }(95 \% \mathrm{Cl})\end{array}$ & $\operatorname{RR}(95 \% \mathrm{Cl})$ & $\begin{array}{c}\text { Rate per } 100 \text { patient- } \\
\text { years }(95 \% \mathrm{Cl})\end{array}$ & $\operatorname{RR}(95 \% \mathrm{Cl})$ \\
\hline Girls & $4.34(3.89-4.84)$ & 1 & $4.34(3.89-4.84)$ & 1 & $3.18(2.82-3.58)$ & 1 \\
\hline Boys & $3.49(3.12-3.90)$ & $0.80(0.70-0.92)$ & $3.49(3.12-3.90)$ & $0.80(0.70-0.92)$ & $2.72(2.41-3.07)$ & $0.86(0.75-0.98)$ \\
\hline \multicolumn{7}{|l|}{ Age (years) } \\
\hline $0.5-4.9$ & $4.01(2.85-5.65)$ & 1 & $4.00(2.82-5.69)$ & 1 & $3.44(2.44-4.86)$ & 1 \\
\hline $5-9.9$ & $2.24(1.85-2.72)$ & $0.56(0.38-0.83)$ & $2.24(1.84-2.72)$ & $0.56(0.38-0.83)$ & $2.46(2.02-2.99)$ & $0.71(0.48-1.05)$ \\
\hline $10-14.9$ & $4.17(3.71-4.69)$ & $1.04(0.72-1.50)$ & $4.17(3.71-4.69)$ & $1.04(0.72-1.52)$ & $3.18(2.80-3.61)$ & $0.92(0.64-1.33)$ \\
\hline $15-20$ & $5.21(4.59-5.91)$ & $1.30(0.89-1.89)$ & $5.21(4.58-5.92)$ & $1.30(0.89-1.91)$ & $2.88(2.49-3.33)$ & $0.84(0.57-1.22)$ \\
\hline \multicolumn{7}{|c|}{ Diabetes duration (years) } \\
\hline$<1$ & $2.32(1.82-2.96)$ & 1 & $2.32(1.82-2.96)$ & 1 & $1.93(1.51-2.48)$ & 1 \\
\hline $1-1.9$ & $3.71(2.98-4.62)$ & $1.60(1.16-2.21)$ & $3.71(2.98-4.63)$ & $1.60(1.16-2.21)$ & $3.47(2.78-4.34)$ & $1.80(1.30-2.48)$ \\
\hline $2-4.9$ & $5.52(4.92-6.20)$ & $2.38(1.82-3.12)$ & $5.52(4.92-6.20)$ & $2.38(1.81-3.12)$ & $4.27(3.77-4.83)$ & $2.21(1.68-2.90)$ \\
\hline$\geq 5$ & $4.65(4.17-5.18)$ & $2.00(1.53-2.62)$ & $4.65(4.15-5.19)$ & $2.00(1.52-2.64)$ & $3.02(2.66-3.42)$ & $1.56(1.18-2.06)$ \\
\hline \multicolumn{7}{|c|}{ Migration background } \\
\hline Yes & $4.66(4.01-5.42)$ & $1.26(1.08-1.48)$ & $4.66(4.01-5.42)$ & $1.26(1.07-1.48)$ & $3.19(2.73-3.74)$ & $1.11(0.95-1.30)$ \\
\hline No & $3.69(3.36-4.06)$ & 1 & $3.69(3.36-4.06)$ & 1 & $2.86(2.57-3.18)$ & 1 \\
\hline \multicolumn{7}{|c|}{ Insulin treatment regimen } \\
\hline Insulin pump & - & - & $3.88(3.42-4.40)$ & $1.00(0.87-1.16)$ & $3.23(2.83-3.69)$ & $1.17(1.01-1.35)$ \\
\hline Insulin injections & - & - & $3.87(3.49-4.29)$ & 1 & $2.77(2.47-3.11)$ & 1 \\
\hline \multicolumn{7}{|c|}{ HbA1c (\%) (mmol/mol) } \\
\hline$<6.0(<42)$ & - & - & - & - & $0.67(0.31-1.41)$ & 1 \\
\hline $6.0-6.9(42-52)$ & - & - & - & - & $1.00(0.77-1.30)$ & $1.50(0.68-3.32)$ \\
\hline $7.0-7.9(53-63)$ & - & - & - & - & $1.94(1.65-2.27)$ & $2.91(1.35-6.25)$ \\
\hline $8.0-8.9(64-74)$ & - & - & - & - & $4.02(3.47-4.65)$ & $6.04(2.82-12.94)$ \\
\hline$\geq 9(\geq 75)$ & - & - & - & - & $14.13(12.61-15.83)$ & $21.22(9.95-45.25)$ \\
\hline
\end{tabular}

adjusted for age, sex, diabetes duration and migration background.

${ }^{\mathrm{b}}$ Adjusted for age, sex, diabetes duration, migration background and treatment regimen.

${ }^{c}$ Adjusted for age, sex, diabetes duration, migration background, treatment regimen and HbA1c category. Several two-factor interactions of the independent variables were found to be statistically significant, but these did not have any clinical relevance (data not shown).

these results indicate no definite association between sex and hospital admission for severe hypoglycemia, but there was a trend for higher admission rates for hypoglycemia with age, while diabetes duration of $>5$ years was associated with lower admission rates for hypoglycemia.

Patients with migration background were admitted more often because of severe hypoglycemia than individuals without migration background (Fig. 2D). These differences remained significant after multivariable adjustment in regression model $1(P<0.001)$, model $2(P=0.001)$ and model $3(P=0.001)$ (Table 4$)$. Migrants had a $67 \%$ higher risk of admission for severe hypoglycemia than non-migrants (Table 4), identifying migration background as a clear risk factor of hospital admission for severe hypoglycemia.

\section{Treatment-related risk of admission for severe hypoglycemia}

Hospitalization because of severe hypoglycemia was found more often in patients with insulin injections compared to individuals using insulin pump therapy (Fig. 2E). This difference was no longer significant after multivariable adjustment in regression model $2(P=0.30)$ and model 3 $(P=0.30)$ (Table 4). Comparisons of individuals within different HbA1c groups showed no trend for unadjusted severe hypoglycemia admission rates between HbA1c groups below 8.9\% (Fig. 2F). Lower rates for severe hypoglycemia were observed for patients with HbA1c $\geq 9 \%$ compared to individuals with HbA1c of $8.0-8.9 \%$ (Fig. 2F), which remained significant in regression model 3 $(P=0.02)$ (Table 4).

Individuals with one or more severe hypoglycemia within the preceding year had more than 40 -fold higher admission rates for severe hypoglycemia than patients without a severe hypoglycemia in the preceding year (17.69 (95\% CI, 15.63-20.03) vs 0.42 (95\% CI, 0.35-0.52), RR 41.91 (95\% CI, 33.10-53.08), $P<0.001$ ), which remained significant after adjustment for age, sex, diabetes duration, migration background, treatment regimen and HbA1c category according to model 3 (18.65 (95\% CI, 16.05-21.65) vs 0.43 (95\% CI, $0.35-0.53)$, RR 43.46 

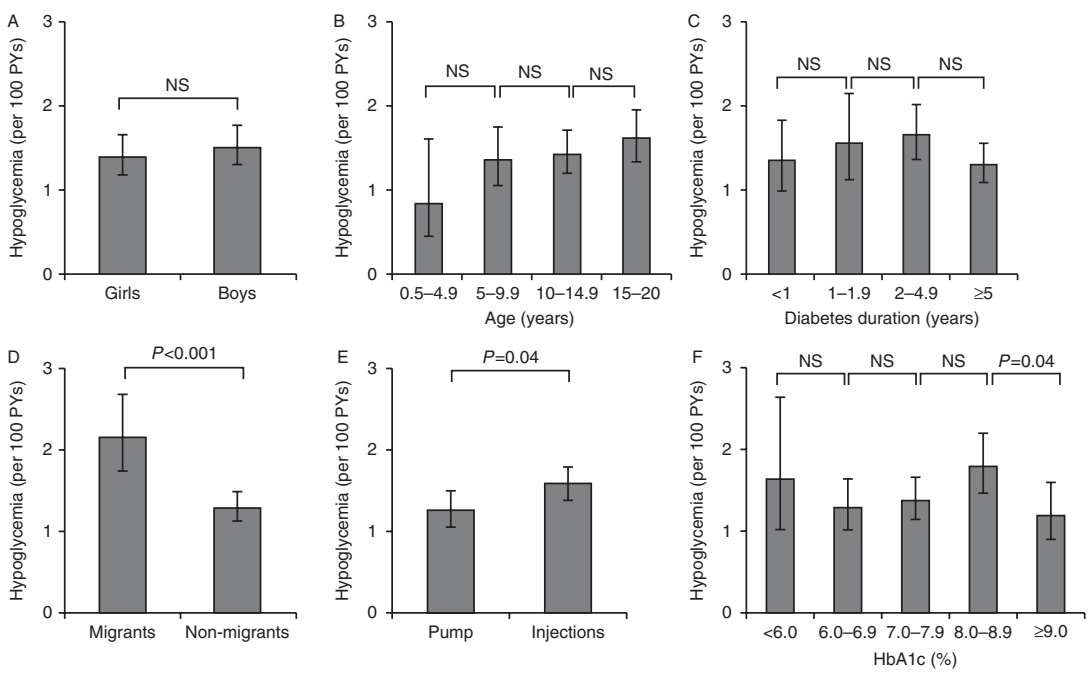

\section{Figure 2}

Unadjusted rates of hospital admission for severe hypoglycemia. Rates per 100 patient-years (PYs) with $95 \% \mathrm{Cl}$ were stratified for: (A) sex, (B) age, (C) diabetes duration,

(95\% CI, 34.15-55.31), $P<0.001)$. Thus, preceding severe hypoglycemia is a major predictor of hospital admission for severe hypoglycemia.

\section{Discussion}

To analyze rates and risk factors of hospital admission for DKA and for severe hypoglycemia in young patients with established type 1 diabetes, we performed an observational study in a prospective cohort of 31330 patients treated between 2011 and 2013 in Germany. We found that ketoacidosis is more common in girls, adolescents and patients with diabetes duration $>1$ year, and that DKA risk strongly increases with HbA1c. Risk of severe hypoglycemia requiring hospital admission was highest in individuals with severe hypoglycemia in the preceding year.

The total rate of hospital admissions for ketoacidosis in this population-based analysis (4.81/100 patient-years) is similar to previous studies (5) and close to former results from the DPV cohort (5.9/100 patient-years) (1), suggesting that the majority of patients with this acute complication in Germany are treated in hospital. Treatment of DKA in children frequently requires hospitalization because experienced nursing staff and specialized pediatricians are needed. However, hyperglycemia and ketosis in individuals without dehydration and vomiting may also be managed at home by parents trained in
(D) migration background, (E) insulin treatment regimen and (F) HbA1c. Conversion for $\mathrm{HbA} 1 \mathrm{c}(\mathrm{mmol} / \mathrm{mol})=(\mathrm{HbA} 1 \mathrm{c}(\%)-$ $2.15) \times 10.929$. NS, not significant.

sick-day management or in an outpatient health care facility (emergency ward) (5).

In our study, girls, adolescents and patients with high HbA1c levels were at an increased risk for ketoacidosis, similar to earlier findings $(5,6,7,14)$. This finding may be explained in part by omitting insulin inattentively, or in order to lose weight (particularly in females), and poor adherence to diabetes treatment which is common in adolescents with erratic meals and risk-taking behavior $(14,15)$. We found an exponential rise of hospital admission rates for ketoacidosis with increasing HbA1c similar to previous reports from North America (6, 7). Thus, poor metabolic control was the strongest predictor of hospital admission for DKA in our study.

Higher DKA rates were seen in patients with diabetes duration of $>1$ year, similar to previous findings $(6,9)$. A plausible explanation for this finding is the complete loss of $\beta$ cell function after that time, while residual insulin secretion in individuals with short diabetes duration may partially protect from DKA. The higher DKA rates found in individuals with migration background correspond to earlier observations $(1,7)$ identifying migrant populations at particular risk for DKA. Lower household income has been identified as DKA risk factor $(6,7)$, but lower adherence to diabetes therapy in immigrant populations related to cultural factors may independently contribute to DKA risk (16). However, our study design did not allow analyzing DKA frequency in relation to socioeconomic and cultural variables. 
Table 4 Adjusted rates and relative risks (RRs) of hospital admission for severe hypoglycemia. Results from $n=30814$ individuals with $\mathrm{HbA} 1 \mathrm{c}$ measurements.

\begin{tabular}{|c|c|c|c|c|c|c|}
\hline \multirow[b]{2}{*}{ Patient group } & \multicolumn{2}{|c|}{ Model $1^{a}$} & \multicolumn{2}{|c|}{ Model $2^{b}$} & \multicolumn{2}{|c|}{ Model $3^{c}$} \\
\hline & $\begin{array}{l}\text { Rate per } 100 \text { patient- } \\
\text { years }(95 \% \mathrm{Cl})\end{array}$ & $\operatorname{RR}(95 \% \mathrm{Cl})$ & $\begin{array}{l}\text { Rate per } 100 \text { patient- } \\
\text { years }(95 \% \mathrm{Cl})\end{array}$ & $\operatorname{RR}(95 \% \mathrm{Cl})$ & $\begin{array}{l}\text { Rate per } 100 \text { patient- } \\
\text { years }(95 \% \mathrm{Cl})\end{array}$ & RR $(95 \% \mathrm{Cl})$ \\
\hline Girls & $1.33(1.11-1.59)$ & 1 & $1.33(1.11-1.59)$ & 1 & $1.30(1.09-1.56)$ & 1 \\
\hline Boys & $1.42(1.21-1.68)$ & $1.07(0.85-1.35)$ & $1.42(1.20-1.68)$ & $1.07(0.85-1.34)$ & $1.39(1.17-1.64)$ & $1.06(0.84-1.34)$ \\
\hline \multicolumn{7}{|l|}{ Age (years) } \\
\hline $0.5-4.9$ & $0.74(0.38-1.42)$ & 1 & $0.79(0.40-1.55)$ & 1 & $0.75(0.38-1.47)$ & 1 \\
\hline $5-9.9$ & $1.23(0.94-1.60)$ & $1.67(0.82-3.36)$ & $1.24(0.95-1.62)$ & $1.57(0.77-3.20)$ & $1.21(0.93-1.59)$ & $1.61(0.79-3.30)$ \\
\hline $10-14.9$ & $1.41(1.17-1.70)$ & $1.92(0.97-3.81)$ & $1.40(1.16-1.69)$ & $1.77(0.88-3.57)$ & $1.37(1.13-1.66)$ & $1.82(0.90-3.68)$ \\
\hline $15-20$ & $1.67(1.35-2.06)$ & $2.27(1.13-4.57)$ & $1.65(1.33-2.04)$ & $2.08(1.01-4.27)$ & $1.63(1.32-2.02)$ & $2.17(1.06-4.48)$ \\
\hline \multicolumn{7}{|c|}{ Diabetes duration (years) } \\
\hline$<1$ & $1.42(1.04-1.94)$ & 1 & $1.38(1.01-1.89)$ & 1 & $1.37(1.00-1.89)$ & 1 \\
\hline $1-1.9$ & $1.62(1.17-2.24)$ & $1.14(0.73-1.77)$ & $1.59(1.15-2.21)$ & $1.15(0.74-1.80)$ & $1.57(1.13-2.18)$ & $1.14(0.73-1.79)$ \\
\hline $2-4.9$ & $1.60(1.31-1.95)$ & $1.12(0.78-1.62)$ & $1.60(1.31-1.96)$ & $1.16(0.80-1.69)$ & $1.56(1.27-1.90)$ & $1.13(0.78-1.65)$ \\
\hline$\geq 5$ & $1.16(0.95-1.41)$ & $0.82(0.56-1.19)$ & $1.19(0.97-1.45)$ & $0.86(0.58-1.26)$ & $1.15(0.94-1.42)$ & $0.84(0.57-1.25)$ \\
\hline \multicolumn{7}{|c|}{ Migration background } \\
\hline Yes & $2.09(1.67-2.61)$ & $1.68(1.30-2.17)$ & $2.06(1.65-2.58)$ & $1.66(1.28-2.15)$ & $2.03(1.62-2.54)$ & $1.67(1.29-2.16)$ \\
\hline No & $1.24(1.07-1.44)$ & 1 & $1.24(1.07-1.44)$ & 1 & $1.22(1.05-1.41)$ & 1 \\
\hline \multicolumn{7}{|c|}{ Insulin treatment regimen } \\
\hline Insulin pump & - & - & $1.26(1.02-1.56)$ & $0.88(0.68-1.13)$ & $1.24(1.00-1.53)$ & $0.88(0.68-1.13)$ \\
\hline Insulin injections & - & - & $1.44(1.23-1.69)$ & 1 & $1.41(1.21-1.66)$ & 1 \\
\hline \multicolumn{7}{|c|}{$\mathrm{HbA1c}(\%)(\mathrm{mmol} / \mathrm{mol})$} \\
\hline$<6.0(<42)$ & - & - & - & - & $1.51(0.90-2.55)$ & $1.37(0.75-2.52)$ \\
\hline $6.0-6.9(42-52)$ & - & - & - & - & $1.24(0.96-1.61)$ & $1.13(0.75-1.69)$ \\
\hline $7.0-7.9(53-63)$ & - & - & - & - & $1.36(1.11-1.68)$ & $1.24(0.86-1.79)$ \\
\hline $8.0-8.9(64-74)$ & - & - & - & - & $1.72(1.36-2.17)$ & $1.56(1.07-2.28)$ \\
\hline$\geq 9(\geq 75)$ & - & - & - & - & $1.10(0.80-1.51)$ & 1 \\
\hline
\end{tabular}

The rate of hospital admissions for severe hypoglycemia in this study (1.45/100 patient-years) is much lower than the total incidence of severe hypoglycemia in the DPV cohort (19.1/100 patient-years (1) and 17.6/patient-years in 2012 (8)), indicating that $<10 \%$ of patients with severe hypoglycemia are admitted to hospital treatment in Germany. These findings may be explained by urgent on-site treatment of trained parents or caregivers with rapid-acting oral sources of glucose or i.m. administration of glucagon (11) or short-term out-patient treatment not necessarily leading to in-patient care in the majority of patients. Unexpected and extemporaneous emergency situations of severe hypoglycemia may lead to hospitalization as well as cases with repeated or unexplained severe hypoglycemia needing detailed diagnostic approach.

Of the demographic variables analyzed in our study, only migration background was associated with higher hospital admission rate for severe hypoglycemia. The higher incidence of admission for severe hypoglycemia in children and adolescents of immigrant parents may be explained in the context of socioeconomic disadvantages $(6,7)$ or due to insufficient diabetes education based on cultural barriers (16). No association between lower HbA1c and hospital admission rate for severe hypoglycemia was found, similar to other reports $(9,13)$. These results correspond to our previous findings in young individuals with type 1 diabetes that low $\mathrm{HbA1c}$ no longer predicts the risk of severe hypoglycemia (8).

The highest rates of hospital admission for severe hypoglycemia were found in individuals with one or more events of severe hypoglycemia in the preceding year. Previous severe hypoglycemia has been nominated as a risk factor for subsequent hypoglycemia $(6,11)$. These findings emphasize the need for detailed evaluation of every severe hypoglycemic episode and, more importantly, specific diabetes counselling in order to prevent hypoglycemia with ongoing diabetes treatment.

We did not find consistent differences between patients using insulin injections and individuals using insulin pumps concerning hospital admission for 
ketoacidosis or severe hypoglycemia. However, direct comparison is difficult in observational data, as patients are not randomized to pump therapy, but specific indications lead to the initiation of insulin pump therapy. In a report from Sweden, twofold higher ketoacidosis rates were described in patients using insulin pumps compared to individuals with type 1 diabetes using insulin injections (14), while more recent studies reported lower ketoacidosis rates in pump users than in those using injections $(7,10)$. There was a trend to a lower rate of hospital admission for severe hypoglycemia in patients using insulin pumps in our cohort but without significant difference after multivariable adjustment. This finding is concordant with other studies reporting lower rates for severe hypoglycemia in patients on insulin pump treatment $(7,10,13)$.

One strength of this study is its population-based multicenter database, including more than 30000 young individuals with established type 1 diabetes, permitting analysis of demographic and treatment variables as risk factors of DKA and of severe hypoglycemia. The study was not intended to investigate different causes of DKA or severe hypoglycemia requiring hospitalization. Our data allow for the identification of individuals with high risk of admission for DKA and for hypoglycemia. These results are of clinical relevance as specific focus may be put on such patients with type 1 diabetes. It has been shown that structured diabetes education may reduce the incidence of DKA and severe hypoglycemia by more than $50 \%(17,18)$ and targeted diabetes counseling in high risk individuals with type 1 diabetes might particularly reduce and prevent these acute complications.

In conclusion, the results of this study identify individuals with type 1 diabetes at-risk of hospital admission for DKA (patients with high HbA1c, diabetes duration $>1$ year, adolescents, girls) and at risk of admission for severe hypoglycemia (patients with preceding hypoglycemia and migration background). These at-risk individuals may need specific attention in diabetes education aiming at the prevention of ketoacidosis and severe hypoglycemia.

\section{Declaration of interest}

The authors declare that there is no conflict of interest that could be perceived as prejudicing the impartiality of the research reported.

\section{Funding}

The work was supported by the Competence Network Diabetes Mellitus, funded by the Federal Ministry of Education and Research (FKZ 01 GI1106 and 01GI1109B), Berlin, Germany, integrated into the German Center for Diabetes Research (DZD) as of January 2015; by the European Foundation for the Study of Diabetes; and by Medtronic Switzerland.

\section{Acknowledgements}

We thank all investigators participating in the DPV Initiative. The following institutions contributed to the present analysis: Aachen-Innere RWTH, Aachen-Uni-Kinderklinik RWTH, Aalen Kinderklinik, Ahlen St. Franziskus Kinderklinik, Altötting-Burghausen Innere, Arnsberg-Hüsten Karolinenhosital Kinderabteilung, Asbach Kamillus-Klinik Innere, Augsburg Innere, Augsburg Kinderklinik Zentralklinikum, Aue Helios Kinderklink, Aurich Kinderklinik, Bad Aibling Internist. Praxis, Bad Hersfeld Kinderklinik, Bad Kösen Kinder-Rehaklinik, Bad Kreuznach-Viktoriastift, Bad Lauterberg Diabeteszentrum Innere, Bad Mergentheim - Diabetesfachklinik, Bad Mergentheim - Gemeinschaftspraxis DM-dorf Alth, Bad Oeynhausen Herz- und Diabeteszentrum NRW, Bad Orb Spessart Klinik, Bad Reichenhall Kreisklinik Innere, Bad Salzungen Kinderklinik, Bad Waldsee Kinderarztpraxis, Bautzen Oberlausitz Kinderklinik, Berchtesgaden CJD, Bayreuth Innere, Berlin DRK-Kliniken, Berlin Endokrinologikum, Berlin LichtenbergKinderklinik, Berlin Oskar Zieten Krankenhaus Innere, Berlin VirchowKinderklinik, Berlin Vivantes Hellersdorf Innere, Berlin Klinik St. Hedwig Innere, Berlin Schlosspark-Klinik Innere, Bremen-Kinderklinik Nord, Bremen-Mitte Innere, Bremen Zentralkrankenhaus Kinderklinik, Bremerhaven Kinderklinik, Bielefeld Kinderklinik Gilead, Bocholt Kinderklinik, Bochum Universitäts-Kinderklinik St. Josef, Böblingen Kinderklinik, Bonn Uni-Kinderklinik, Bottrop Knappschaftskrankenhaus Innere, Braunschweig Kinderarztpraxis, Celle Klinik für Kinder- und Jugendmedizin, Chemnitz Kinderklinik, Coburg Kinderklinik, Coesfeld/Dülmen Innere, Coesfeld Kinderklinik, Darmstadt Innere, Darmstadt Kinderklinik Prinzessin Margaret, Datteln Vestische Kinderklinik, Deggendorf Medizinische Klinik II, Delmenhorst Kinderklinik, Dessau Kinderklinik, Detmold Kinderklinik, Dinslaken Kinderklinik, Dortmund-Hombruch Marienhospital, Dortmund Kinderklinik, Dortmund Knappschaftskrankenhaus Innere, Dortmund Medizinische Kliniken Nord, Dortmund St. Josefs-Hospital Innere, Dresden Neustadt Kinderklinik, Dresden Uni-Kinderklinik, Düren-Birkesdorf Kinderklinik, Düsseldorf Uni-Kinderklinik, Duisburg-Huckingen, Duisburg Kinderklinik, Duisburg Malteser St. Anna Innere, Duisburg Malteser St. Johannes, Duisburg-St. Johannes Helios, Eisleben Lutherstadt Helios-Klinik, Erfurt Kinderklinik, Erlangen Uni Innere, Erlangen Uni-Kinderklinik, Essen Elisabeth Kinderklinik, Essen Kinderarztpraxis, Essen Diabetes-Schwerpunktpraxis, Essen Uni-Kinderklink, Esslingen Klinik für Kinder- und Jugendliche, Eutin Kinderklinik, Filderstadt Kinderklinik, Forchheim Diabeteszentrum SPP, Freudenstadt Kinderklinik, Frankenthal Kinderarztpraxis, Frankfurt Diabeteszentrum Rhein-Main-Erwachsenendiabetes, Frankfurt Diabeteszentrum Rhein-Main-pädiat. Diabetes, Frankfurt UniKlinik Innere, Frankfurt Uni-Kinderklinik, Freiburg Kinder-MVZ, Freiburg St. Josef Kinderklinik, Freiburg Uni-klinik Innere, Freiburg Uni-Kinderklinik, Friedberg Innere Klinik, Fürth Kinderklinik, Fulda Kinderklinik, Gaissach Fachklinik der Deutschen Rentenversicherung, Garmisch-Partenkirchen Kinderklinik, Geislingen Klinik Helfenstein Innere, Gelnhausen Innere, Gelnhausen Kinderklinik, Gelsenkirchen Kinderklinik Marienhospital, Gera Kinderklinik, Gießen Ev. Krankenhaus Mittelhessen, Gießen Uni-Kinderklinik, Göppingen Kinderklinik am Eichert, Görlitz Städtische Kinderklinik, Göttingen Uni-Kinderklinik, Güstrow Innere, Hachenburg Kinderpraxis, Hagen Kinderklinik, Halberstadt Kinderklinik St. Salvator, Halle Uni-Kinderklinik, Hameln Kinderklinik, Hamm Kinderklinik, Hamburg Altonaer Kinderklinik, Hamburg Endokrinologikum, Hamburg Kinderklinik Wilhelmstift, Hamburg-Nord Kinder-MVZ, Hanau Kinderklinik, Hannover Kinderklinik auf der Bult, Hannover Kinderklinik $\mathrm{MHH}$, Haren Kinderarztpraxis, Heide Kinderklinik, Heidelberg St. Josefskrankenhaus, Heidelberg Uni-Kinderklinik, Heidenheim Kinderklinik, Heilbronn Innere Klinik, Heilbronn Kinderklinik, Herdecke Kinderklinik, Herford Innere Medizin I, Herford Kinderarztpraxis, Herford Klinikum Kinder and Jugendliche, Heringsdorf Inselklinik, Herne Evangelisches Krankenhaus Innere, Herten 
St. Elisabeth Innere, Hildesheim Kinderklinik, Hildesheim Kinderarztpraxis, Hildesheim GmbH Innere, Hof Kinderklinik, Homburg Uni-Kinderklinik Saarland, Iserlohn Innere Medizin, Itzehoe Kinderklinik, Jena Uni-Kinderklinik, Kaiserslautern Kinderarztpraxis, Kaiserslautern-Westpfalzklinikum Kinderklinik, Kamen Klinikum Westfalen Hellmig Krankenhaus, Karlsburg Klinik für Diabetes and Stoffwechsel, Karlsruhe Städtische Kinderklinik, Kassel Klinikum Kinder- und Jugendmedizin, Kiel Städtische Kinderklinik, Kiel Universitäts-Kinderklinik, Kirchen DRK Klinikum Westerwald Kinderklinik, Kirchheim-Nürtingen Innere, Kleve Innere, Koblenz Kinderklinik Kemperhof, Kempten Oberallgäu Kinderklinik, Köln Kinderklinik Amsterdamerstrasse, Köln Uni-Kinderklinik, Konstanz Innere Klinik, Konstanz Kinderklinik, Kreischa-Zscheckwitz Klinik Bavaria, Krefeld Innere Klinik, Krefeld Kinderklinik, Krefeld-Uerdingen St. Josef Innere, Lappersdorf Kinderarztpraxis, Landshut Kinderklink, Leer KreiskrankenhausKinderabteilung, Leipzig Uni-Kinderklinik, Leverkusen Kinderklinik, Lilienthal Schwerpunktpraxis, Limburg Innere, Lingen Kinderklinik St. Bonifatius, Lippstadt Evangelische Kinderklinik, Lübeck Uni-Kinderklinik, Lübeck Uni-Klinik Innere, Lüdenscheid Hilfswerk Kinder and Jugendliche, Ludwigsburg Kinderklinik, Ludwigshafen diabetol. SPP, Ludwigshafen Kinderklinik St. Anna-Stift, Lüdenscheid Märkische Kliniken-Kinder and Jugendmedizin, Magdeburg Städtisches Klinikum Innere, Magdeburg UniKinderklinik, Mainz Uni-Kinderklinik, Mannheim Uni-Kinderklinik, Marktredwitz Innere, Mechernich Kinderklinik, Meissen Kinderklinik Elblandklinikum, Memmingen Kinderklinik, Minden Kinderklinik, Moers Kinderklinik, Mönchengladbach Kinderklinik Rheydt Elisabethkrankenhaus, Mühldorf Gemeinschaftspraxis, München Diabetes-Zentrum Süd, München-Gauting Kinderarztzentrum, München 3. Orden Kinderklinik, München Kinderarztpraxis Diabet. SPP, München-Schwabing Kinderklinik, München von Haunersche Kinderklinik, München-Harlaching Kinderklinik, Münster Clemens-Hospital Innere, Münster Herz Jesu Innere, Münster St. Franziskus Kinderklinik, Münster pädiat. Schwerpunktpraxis, Münster UniKinderklinik, Murnau am Staffelsee - Diabetol. SPP, Mutterstadt Kinderarztpraxis, Nauen Havellandklinik, Neuburg Kinderklinik, Neumarkt Innere, Neunkirchen Marienhausklinik Kohlhof Kinderklinik, Neuss Lukaskrankenhaus Kinderklinik, Neuwied Kinderklinik Elisabeth, Neuwied Marienhaus Klinikum St. Elisabeth Innere, Nürnberg Cnopfsche Kinderklinik, Nürnberg Zentrum für Neugeborene, Kinder and Jugendliche, Oberhausen Innere, Oberhausen Kinderklinik, Oberhausen Kinderarztpraxis, Oberhausen St. Clemens Hospitale Sterkrade, Offenbach/Main Innere, Offenbach/Main Kinderklinik, Offenburg Kinderklinik, Oldenburg Kinderklinik, Oldenburg Schwerpunktpraxis, Olpe Pädiatrische Gemeinschaftspraxis, Osnabrück Christliches Kinderhospital, Paderborn St. Vincenz Kinderklinik, Papenburg Marienkrankenhaus Kinderklinik, Passau Kinderarztpraxis, Passau Kinderklinik, Pforzheim Kinderklinik, Pfullendorf Innere, Pirmasens Städtisches Krankenhaus Innere, Plauen Vogtlandklinikum, Rastatt Kreiskrankenhaus Innere, Ravensburg Kinderklink St. Nikolaus, Regensburg Kinderklinik St. Hedwig, Rendsburg Kinderklinik, Reutlingen Klinikum Steinenberg Innere, Reutlingen Kinderarztpraxis, Reutlingen Kinderklinik, Rheine Mathiasspital Kinderklinik, Rosenheim Innere, Rosenheim Kinderklinik, Rosenheim Schwerpunktpraxis, Rostock Uni-Kinderklinik, Rotenburg/Wümme Kinderklinik, Rüsselsheim Kinderklinik, Saaldorf-Surheim Diabetespraxis, Saalfeld Thüringenklinik Kinderklinik, Saarbrücken Kinderklinik Winterberg, Saarlouis Kinderklinik, Scheidegg Prinzregent Luitpold, St. Augustin Kinderklinik, Schwäbisch Gmünd Stauferklinik Kinderklinik, Schwäbisch Hall Diakonie Kinderklinik, Schweinfurt Kinderklinik, Schwerin Innere, Schwerin Kinderklinik, Siegen Kinderklinik, Singen-Hegauklinik Kinderklinik, Singen Kinderarztpraxis, Spaichingen Innere, Stade Kinderklinik, Stolberg Kinderklinik, Stuttgart Olgahospital Kinderklinik, Suhl Kinderklinik, Sylt Rehaklinik, Tettnang Innere, Traunstein diabetologische Schwerpunktpraxis, Trier Kinderklinik der Borromäerinnen, Trostberg Innere, Tübingen Uni-Kinderklinik, Ulm Endokrinologikum, Ulm Schwerpunktpraxis Bahnhofsplatz, Ulm Uni Innere, Ulm Uni-Kinderklinik, Vechta Kinderklinik, Viersen Kinderkrankenhaus St. Nikolaus, Villingen-Schwenningen Diabetesschule, Villingen-Schwenningen Schwarzwald-Baar-Klinikum Innere, Waldshut Kinderpraxis, Waldshut-Tiengen Kinderpraxis Biberbau,
Waiblingen Kinderklinik, Waren-Müritz Kinderklinik, Weiden Kinderklinik, Weingarten Kinderarztpraxis, Weisswasser Kreiskrankenhaus, Wernberg-Köblitz SPP, Wiesbaden Horst-Schmidt-Kinderkliniken, Wiesbaden Kinderklinik DKD, Wilhelmshaven Reinhard-Nieter-Kinderklinik, Wismar Kinderklinik, Wittenberg Innere, Wittenberg Kinderklinik, Wolgast Innere, Worms Kinderklinik, Worms-Weierhof, Wuppertal Kinderklinik, Zweibrücken Ev. Krankenhaus Innere.

\section{References}

1 Rosenbauer J, Dost A, Karges B, Hungele A, Stahl A, Bächle C, Gerstl EM, Kastendieck C, Hofer SE \& Holl RW. Improved metabolic control in children and adolescents with type 1 diabetes: a trend analysis using prospective multicenter data from Germany and Austria. Diabetes Care 201235 80-86. (doi:10.2337/dc11-0993)

2 Skrivarhaug T, Bangstad HJ, Stene LC, Sandvik L, Hanssen KF \& Joner G. Long-term mortality in a nationwide cohort of childhood-onset type 1 diabetic patients in Norway. Diabetologia 200649 298-305. (doi:10.1007/s00125-005-0082-6)

3 Feltbower RG, Bodansky HJ, Patterson CC, Parslow RC, Stephenson CR, Reynolds C \& McKinney PA. Acute complications and drug misuse are important causes of death for children and young adults with type 1 diabetes: results from the Yorkshire Register of diabetes in children and young adults. Diabetes Care 200831 922-926. (doi:10.2337/ dc07-2029)

4 Patterson CC, Dahlquist G, Harjutsalo V, Joner G, Feltbower RG, Svensson J, Schober E, Gyürüs E, Castell C, Urbonaité B et al. Early mortality in EURODIAB population-based cohorts of type 1 diabetes diagnosed in childhood since 1989. Diabetologia 200750 2439-2442. (doi:10.1007/s00125-007-0824-8)

5 Wolfsdorf JI, Allgrove J, Craig ME, Edge J, Glaser N, Jain V, Lee WW, Mungai LN, Rosenbloom AL, Sperling MA et al. Diabetic ketoacidosis and hyperglycemic hyperosmolar state. Pediatric Diabetes 201415 (Suppl 20) 154-179. (doi:10.1111/pedi.12165)

6 Rewers A, Chase HP, Mackenzie T, Walravens P, Roback M, Rewers M, Hamman RF \& Klingensmith G. Predictors of acute complications in children with type 1 diabetes. Journal of the American Medical Association 2002287 2511-2518. (doi:10.1001/jama.287.19.2511)

7 Cengiz E, Xing D, Wong JC, Wolfsdorf JI, Haymond MW, Rewers A, Shanmugham S, Tamborlane WV, Willi SM, Seiple DL et al. Severe hypoglycemia and diabetic ketoacidosis among youth with type 1 diabetes in the T1D Exchange clinic registry. Pediatric Diabetes 201314 447-454. (doi:10.1111/pedi.12030)

8 Karges B, Rosenbauer J, Kapellen T, Wagner VM, Schober E, Karges W \& Holl RW. Hemoglobin A1c levels and risk of severe hypoglycemia in children and young adults with type 1 diabetes from Germany and Austria: a trend analysis in a cohort of 37,539 patients between 1995 and 2012. PLoS Medicine 201411 e1001742. (doi:10.1371/journal. pmed.1001742)

9 O'Connell SM, Cooper MN, Bulsara MK, Davis EA \& Jones TW. Reducing rates of severe hypoglycemia in a population-based cohort of children and adolescents with type 1 diabetes over the decade 2000-2009. Diabetes Care 201134 2379-2380. (doi:10.2337/ dc11-0748)

10 Johnson SR, Cooper MN, Jones TW \& Davis EA. Long-term outcome of insulin pump therapy in children with type 1 diabetes assessed in a large population-based case-control study. Diabetologia 201356 2392-2400. (doi:10.1007/s00125-013-3007-9)

11 Ly TT, Maahs DM, Rewers A, Dunger D, Oduwole A \& Jones TW. Assessment and management of hypoglycemia in children and adolescents with diabetes. Pediatric Diabetes 201415 (Suppl 20) 180-192. (doi:10.1111/pedi.12174)

12 Jacobson AM, Musen G, Ryan CM, Silvers N, Cleary P, Waberski B, Burwood A, Weinger K, Bayless M, Dahms W et al. Long-term effect 
of diabetes and its treatment on cognitive function. New England Journal of Medicine 2007356 1842-1852. (doi:10.1056/ NEJMbkrev57613)

13 Katz ML, Volkening LK, Anderson BJ \& Laffel LM. Contemporary rates of severe hypoglycaemia in youth with type 1 diabetes: variability by insulin regimen. Diabetic Medicine 201229 926-932. (doi:10.1111/ j.1464-5491.2012.03646.x)

14 Hanas R, Lindgren F \& Lindblad B. A 2-yr national population study of pediatric ketoacidosis in Sweden: predisposing conditions and insulin pump use. Pediatric Diabetes 200910 33-37. (doi:10.1111/j.1399-5448. 2008.00441.x)

15 Cameron FJ, Amin R, de Beaufort C, Codner E \& Acerini CL. Diabetes in adolescence. Pediatric Diabetes 201415 (Suppl 20) 245-256. (doi:10.1111/pedi.12169)
16 Tubiana-Rufi N, Moret L, Czernichow P \& Chwalow J. Risk factors for poor glycemic control in diabetic children in France. Diabetes Care 1995 18 1479-1482. (doi:10.2337/diacare.18.11.1479)

17 Sämann A, Mühlhauser I, Bender R, Hunger-Dathe W, Kloos C \& Müller UA. Flexible intensive insulin therapy in adults with type 1 diabetes and high risk for severe hypoglycemia and diabetic ketoacidosis. Diabetes Care 200629 2196-2199. (doi:10.2337/ dc06-0751)

18 Elliott J, Jacques RM, Kruger J, Campbell MJ, Amiel SA, Mansell P, Speight J, Brennan A \& Heller SR. Substantial reductions in the number of diabetic ketoacidosis and severe hypoglycaemia episodes requiring emergency treatment lead to reduced costs after structured education in adults with type 1 diabetes. Diabetic Medicine 201431 847-853. (doi:10.1111/dme.12441)

Received 3 February 2015

Revised version received 12 June 2015

Accepted 17 June 2015 